\title{
Ley Zamudio en perspectiva. Derecho Antidiscriminación chileno frente a los estándares de la Unión Europea ${ }^{12}$
}

\author{
Zamudio Law in perspective. Chilean Anti-Discrimination Law against European Union \\ Standards
}

\section{Ignacio Sánchez González}

ignacio.sanchez@derecho.uchile.cl

Estudiante de Derecho de la Facultad de Derecho de la Universidad de Chile. Colaborador del Departamento de Derecho Internacional de la Facultad de Derecho y del Instituto de Estudios Internacionales de la Universidad de Chile.

Resumen: En el marco de los cambios socioculturales que Chile ha experimentado en los últimos años, se hace necesario repensar la fórmula adoptada por el legislador para combatir la discriminación. En el presente trabajo se sigue como fuente las experiencias de la doctrina y jurisprudencia europeas antidiscriminación, tomando en consideración el derecho internacional de los derechos humanos, los fundamentos generales del derecho europeo, los diversos tipos de discriminación, y aspectos procesales de los litigios en esta materia. Clarificada esa base dogmática, el autor compara la legislación y práctica chilena en comento con la europea, tras exponer que la denominada "Ley Zamudio" se gestó con fuertes incidencias del entonces proyecto de Constitución Europea, mas en los hechos, los estándares modelo no se cumplen.

Palabras Clave: Ley Zamudio, Ley Antidiscriminación, Tribunal Europeo de Derechos Humanos, Unión Europea, no discriminación, carga de la prueba.

Abstract: Within the framework of the socio-cultural changes that Chile has experienced in recent years, it is necessary to reconsider the formula adopted by lawmakers to combat discrimination. The present paper follows as its source the experiences of European anti-discrimination doctrine and jurisprudence, taking into consideration international buman rights law, the general foundations of European law, the various types of discrimination, and procedural aspects of litigation in this area. Once this dogmatic basis has been clarified, the author compares the Chilean legislation in issue with European practice, after stating that the so-called "Zamudio Law" was conceived with strong implications of the former European Constitutional Treaty, but in fact, these standards are not fully met.

Artículo enviado el 21.12.2018 y aceptado el 10.12.2019.

2 El presente artículo fue originalmente escrito para el curso "Derecho Comunitario y de la Integración", a cargo de la Prof. Dra. Ana María Moure Pino, en la Facultad de Derecho de la Universidad de Chile. 
Ley Zamudio en perspectiva. Derecho Antidiscriminación chileno frente a estándares de la Unión Europea Ignacio Sánchez González

Key Words: Zamudio Law, Anti-Discrimination Law, European Court of Human Rights, European Union, Non-discrimination, Burden of proof.

\section{Introducción}

En el presente trabajo se esbozará un estudio respecto del Derecho Antidiscriminación existente en Chile, en relación con el derecho internacional de los derechos humanos y con el derecho comparado de la Unión Europea. Para comenzar, es preciso señalar que la única consagración positiva existente en cuanto acción antidiscriminación en nuestro ordenamiento jurídico, distinta al recurso o acción de protección ${ }^{3}$, es la Ley 20.609 (Ley Antidiscriminación, en adelante, LAD), o socialmente conocida como "Ley Zamudio", la cual merece algunos comentarios en lo concerniente a su regulación sustantiva y aplicación a la luz de la evolución del derecho internacional sobre la materia.

Este estudio a la ley en cuestión se centrará en un examen frente a los estándares internacionales, especialmente la doctrina y jurisprudencia de la Unión Europea (en adelante, UE o la Unión) en cuanto a discriminación. Tras ello, intentaremos demostrar que la acción antidiscriminación contenida en la Ley Zamudio no cumple con los estándares mínimos comparados para ofrecer adecuada protección a la víctima.

En tal sentido, y para generar concordancia en el estudio, abordaremos en primer lugar la tramitación en el Congreso Nacional del "proyecto de ley que establece medidas contra la discriminación”, pues, en su discusión parlamentaria mucho se dijo sobre los estándares que debería haber seguido la ley, con especial atención al principio de no discriminación asentado expresamente en el proyecto de Constitución Europea (en adelante, CE) ${ }^{4}$, instrumento jurídico

3 Definido como "la acción constitucional que cualquier persona puede interponer ante los tribunales superiores, a fin de solicitarles que adopten inmediatamente las providencias que juzguen necesarias para restablecer el imperio del derecho y asegurarle la debida protección, frente a un acto u omisión arbitraria o ilegal que importe una privación, perturbación o amenaza al legítimo ejercicio de los derechos y garantías que el constituyente establece, sin perjuicio de los demás derechos que pueda hacer valer ante la autoridad o los tribunales correspondientes" (Maturana y Mosquera, 2012). Vale decir, el recurso de protección se basa en un derecho o garantía constitucional directamente.

4 "En el caso de los valores [de la CE] se añade el de dignidad humana e igualdad y se precisa la caracterización de la sociedad (europea) por el pluralismo, la tolerancia, la justicia, la solidaridad y la no discriminación" (Martín y Pérez de Nanclares, 2003). 
que, pese a no prosperar, sirvió de base para el desarrollo de dichos patrones internacionales, por lo que siguen igual de vigentes.

Posteriormente, se pretende dilucidar los estándares sobre discriminación que la Unión Europea, como organización internacional sui generis, ha logrado asentar.

Finalmente, se hablará de la promulgada Ley $\mathrm{N}^{\circ} 20.609$ en su faz sustantiva y práctica, para responder a la pregunta inicial sobre si se cumplen o no los estándares antidiscriminación de la Unión.

\section{Proyecto legislativo antidiscriminación. Propósito y estándares modelos en la historia de la ley}

A fines de marzo del año 2012 remecía al país un acerbo episodio en Santiago, donde un grupo de jóvenes, de forma brutal, golpearon y torturaron durante varias horas a Daniel Zamudio, dejándolo en estado agonizante en un transitado y conocido parque de la ciudad, joven que horas más tarde muere producto del acto cometido en su contra motivado por el odio y la intolerancia hacia su orientación sexual no normalizada. Su nombre se vuelve automáticamente parte de la bandera de lucha de organizaciones civiles en pos de los derechos humanos, con especial atención a los derechos LGBTQI ${ }^{5}$. Este crimen sensibilizó profundamente tanto a la sociedad civil como a la institucionalidad política, por lo que el entonces presidente Sebastián Piñera decide poner suma urgencia al proyecto de ley que establece medidas contra la discriminación.

Pero la iniciativa legislativa no era circunstancial, sino que el proyecto se encontraba ingresado desde hace años sin llamar especial atención en los gobiernos de turno. En marzo de 2005, bajo el gobierno de Ricardo Lagos, fue ingresado por primera vez ante la Cámara de Diputados un proyecto de ley que establecía medidas contra la discriminación. El Ejecutivo mediante el Mensaje Presidencial No 315-352 a la Cámara de Diputados, puso especial atención al efecto de la globalización en las legislaciones locales y que este proceso implica por sí sociedades más diversas. Así, se dijo que "[e]sta diversidad plantea una serie de desafíos al Estado y a sus gobiernos, teniendo siempre presente que uno de los deberes primordiales de éste consiste en estar al servicio de la persona humana y que su finalidad es promover el bien común, asegurando el derecho de las personas a participar con igualdad de oportunidades en la vida nacional" (Biblioteca del Congreso Nacional, 2005: 5).

5 La sigla alude a lesbiana, gay, bisexual, transgénero, queer e intersexual. 
Se dijo también, refiriéndose a la Declaración Universal de Derechos Humanos, que "[se marcó] un hito histórico y diferenciador al comprometerse a reconocer y respetar la dignidad intrínseca y los derechos fundamentales de todos los seres humanos, entre los que se encuentra la no discriminación". El Ejecutivo recordó que el principio de no discriminación se encuentra recogido en una multiplicidad de convenios internacionales ratificados por Chile, y para nombrar sólo algunos en esta instancia, incorporan el principio la Convención Americana de Derechos Humanos $(\mathrm{CADH})^{6}$, el Pacto Internacional de Derechos Civiles y Políticos (PIDCP) ${ }^{7}$, la Convención Contra la Tortura y Otros Tratos o Penas Crueles, Inhumanos o Degradantes $^{8}$, la Convención Sobre la Eliminación de Todas las Formas de Discriminación Contra la Mujer ${ }^{9}$ y la Convención Sobre los Derechos del Niño ${ }^{10}$.

Un primer punto destacable, es que desde un inicio el Estado de Chile reconoce que parte importante -si no fundamental- de la inspiración de esta ley lo conforma el derecho internacional de los derechos humanos, legislación que convive expresamente con el principio de no discriminación. En efecto, los tratados mencionados, por regla general se refieren a la discriminación como una práctica que debe ser erradicada con el esfuerzo de los Estados ${ }^{11}$.

Cabe advertir que ya el Consejo de Europa ${ }^{12}$ a través de su historia ha establecido férreamente el principio de no discriminación, cada vez interpretado más extensivamente por el Tribunal Europeo de Derechos Humanos $(\mathrm{TEDH})^{13}$. En este sentido, el TEDH ha ido desarrollando

\footnotetext{
OEA, ratificada en 1990.

ONU, ratificado en 1972.

ONU, ratificada en 1988.

ONU, ratificada en 1989.

10 ONU, ratificada en 1990.
}

11 En este sentido, la Declaración Universal de Derechos Humanos en sus artículos 2.1 y 7 , establece la prohibición de discriminación y la igualdad ante la ley, respectivamente; la $\mathrm{CADH}$ en su artículo 1.1 prescribe: "Los Estados Partes en esta Convención se comprometen a respetar los derechos y libertades reconocidos en ella y a garantizar su libre y pleno ejercicio a toda persona que esté sujeta a su jurisdicción, sin discriminación alguna por motivos de raza, color, sexo, idioma, religión, opiniones políticas o de cualquier otra índole, origen nacional o social, posición económica, nacimiento o cualquier otra condición social"; y el artículo 2 del PIDCP indica la prohibición de discriminación en consideración a una serie de características personales y a "cualquier otra condición social".

12 En 1949 nació el Consejo de Europa. "Plenamente vigente en la actualidad, dicha organización internacional se encuentra basada en el respeto de ciertos valores fundamentales comunes a los Estados europeos -la Democracia, el Estado de Derecho y la protección de los derechos humanos-, y cuenta actualmente con cuarenta y siete Estados miembros, los cuales representan casi la totalidad del continente europeo" (Juri, 2013). La organización actualmente actúa paralelamente a la UE.

13 A modo de ejemplo, y adelantando lo que se dirá infra, el TEDH (instituido en virtud del Convenio Europeo de Derechos Humanos, $\mathrm{CEDH}$ ) ha dado importantes avances en cuanto a la extensión de la interpretación del artículo 14 del CEDH, el cual reza que "[e]l goce de los derechos y libertades reconocidos en el presente Convenio ha de ser asegurado sin distinción alguna, especialmente por razones de sexo, raza, color, lengua, religión, opiniones políticas u otras, origen nacional o social, pertenencia a una minoría nacional, fortuna, nacimiento o cualquier otra situación". Ya desde 1999, en el Asunto Salgueiro da Mouta Silva con Portugal, se 
una sólida línea jurisprudencial, haciendo una sana aplicación del derecho, al estimar la no discriminación como derecho humano, y así ha fallado a favor múltiples pretensiones sustentadas en el artículo 14 del Convenio Europeo de Derechos Humanos $(\mathrm{CEDH})^{14}$.

En relación al proyecto de LAD, se dijo en el primer apartado que la normativa desarrollada en Europa fue un importante modelo que pretendía adoptar la ley, y ello fue objeto de complejas discusiones en su tramitación. Concretamente, la ley en su redacción original se inspiró además de la directiva antidiscriminación del Consejo Europeo que se verá infra- por un inédito proceso que se llevaba a cabo en Europa en esos años: se discutía allá la implementación de una Constitución Europea (CE) ${ }^{15}$. Hasta marzo de 2005, fecha en que se presenta el proyecto de ley antidiscriminación a la Cámara de Diputados, el proyecto de Constitución Europea había sido aprobado por Grecia, Hungría, Italia, Lituania, Eslovenia y España, mientras que la mayoría del resto de los Estados de la Unión habían fijado el proceso de aprobación durante el mismo año.

La innovación del sistema jurídico chileno en materia de discriminación siguió muy de cerca la eventual Constitución Europea, pues correctamente se ha dicho que este original proceso, único en su historia, fue tan atractivo para otras regiones del mundo porque la comunidad europea en su conjunto estaba mostrando señales inequívocas de querer consolidar la paz y el progreso (Ortega, 2001).

El proyecto de ley que establece medidas contra la discriminación, en su versión original, se inspiró en los sólidos esfuerzos mancomunados de la Unión por llevar una agenda antidiscriminación común. Es infructuoso comentar en demasía lo que la Constitución Europea pretendía, pues el proyecto fracasó. No obstante, tres disposiciones de la intentada $\mathrm{CE}$ son atingentes al tema en cuestión, pues actualmente, de una u otra forma, se encuentran igualmente recogidas en el Tratado de Lisboa. Se ha dicho que este último y la CE serían "una misma cosa" $\left(\right.$ Serrano, 2010) ${ }^{16}$, e incluso que "[e]l 29 de octubre de 2004, los 25 Estados

declaró en la sentencia que "hubo una diferencia de trato [...] basada en la orientación sexual del demandante, noción que se contempla, sin duda, en el art. 14 del Convenio".

14 Precisamente, el TEDH ha interpretado extensivamente el principio de no discriminación al encontrar responsabilidad estatal tanto por actos, como por incluso legislaciones discriminatorias. En este sentido, se verá infra que el Tribunal ha conocido causas de la más diversa índole, tales como expulsiones del ejército a personas en consideración a su orientación sexual; el tratamiento policial o de particulares en contra de homosexuales; adopción; matrimonio, etc.

15 Véase el Primer Informe de la Comisión de Derechos Humanos (Biblioteca del Congreso Nacional, 2005: 44): "La Constitución [Europea] introduce explícitamente los principios de igualdad y de no discriminación entre los valores sobre los que se asienta la Unión. El texto las considera disposiciones de aplicación general que la Unión tiene la obligación de promover en la definición y aplicación de sus políticas y acciones. Entre los artículos de la Constitución Europea se encuentran varios relacionados con la no discriminación".

16 Serrano (2010: 136) expone que, tras el fracaso de la CE, se inició un "proceso que busca salvar lo que se considera la 'esencia' del Tratado constitucional, es decir, la arquitectura institucional y, más precisamente, el nuevo modelo de torna de decisiones en el seno del Consejo de la Unión". 
miembros de la Unión, más Bulgaria, Rumania y Turquía, firmaron el Tratado constitucional, [y que a] partir de entonces comenzó un proceso de ratificación que concluyó con la firma el 13 de diciembre de 2007 del Tratado de Lisboa". Más allá de las comparaciones, la no discriminación ocupó parte importante del proyecto, y dada su importancia, los principios y artículos de la CE que serán citados no fueron suprimidos junto al ideal de la supranacionalidad en su máxima expresión, en efecto, se dice que el Tratado de Lisboa del año 2007 recoge cerca de "un 90 por 100 de los avances y reformas de la Constitución Europea" (Ginea y Aldecoa, 2008). Las disposiciones referidas son:

- Artículo I-2, sobre valores de la Unión: "La Unión se fundamenta en los valores de respeto a la dignidad humana, libertad, democracia, igualdad, Estado de Derecho y respeto a los derechos humanos. Estos valores son comunes a los Estados miembros en una sociedad caracterizada por el pluralismo, la tolerancia, la justicia, la solidaridad y la no discriminación".

- Artículo I-3, número 3, sobre los objetivos de la Unión: "3. La Unión combatirá la marginación social y la discriminación y fomentará la justicia y la protección sociales, la igualdad entre mujeres y hombres, la solidaridad entre las generaciones y la protección de los derechos del niño".

- Artículo II-21, sobre valores fundamentales de la Unión y tipos de discriminación: "1. Se prohíbe toda discriminación, y en particular la ejercida por razón de sexo, raza, color, orígenes étnicos o sociales, características genéticas, lengua, religión o convicciones, opiniones políticas o de cualquier otro tipo, pertenencia a una minoría nacional, patrimonio, nacimiento, discapacidad, edad u orientación sexual.

2. Se prohíbe toda discriminación por razón de nacionalidad en el ámbito de aplicación de la Constitución y sin perjuicio de sus disposiciones específicas."

Con lo dicho, y sin necesidad de redundar en ello, se ha puesto de manifiesto que como antesala al proyecto de LAD se encuentra inmediatamente la experiencia comparada, con especial atención en la Unión Europea, en virtud de la cual el legislador avizora la posibilidadnecesidad de contar con una acción especial antidiscriminación, diferenciada de la típica acción de protección constitucional que se entabla ante la Corte de Apelaciones respectiva. La acción constitucional, o recurso de protección, "permite una tutela urgente de derechos fundamentales, permitiendo una aplicación directa por los tribunales ordinarios de justicia de preceptos constitucionales referidos a derechos fundamentales" (Bordalí, 2001) ${ }^{17}$, cuestión

17 El artículo referenciado ofrece nociones fundamentales de la acción de protección, y junto a ello, el autor realiza una reseña histórico-política sobre la creación del recurso de protección durante la dictadura cívico 
distinta al propósito de la ley comentada, pues ella, conforme con su proyecto original tenía por objeto "prevenir y eliminar todas las formas de discriminación que se ejerzan contra cualquier persona" (art. 1 del proyecto original), estableciendo así una acción especial fundada en determinadas causales establecidas por el legislador.

En síntesis, se puede apreciar en la historia de la ley que el proyecto Antidiscriminación tuvo presente algunas constituciones de la región que contienen un principio de no discriminación expreso, como la colombiana (art. 13.2), venezolana (art. 21), puertorriqueña (art. II, sección 1), brasileña (art. $3 \mathrm{n}^{\circ}$ 4) y ecuatoriana (art. $11 \mathrm{n}^{\circ}$ 2); pero es nítido que el patrón comparado más rico en teorización doctrinaria antidiscriminación y de aplicación efectiva, es el que se ha logrado asentar tanto en el Consejo de Europa como en la misma UE, tras la aprobación de la Directiva del Consejo (de la UE) del año 2000 sobre el establecimiento de un programa de acción comunitario para luchar contra la discriminación (Directiva del Consejo 2000/78/CE), y así se reflejó claramente en el Mensaje del Ejecutivo a la Cámara de Diputados, que reconoce además que en Europa este principio es ya una "regla general" (Biblioteca del Congreso Nacional, 2005: 575). Esas bases fueron el germen que el derecho chileno tenía a la vista, además de ser un mínimo ético como señal política hacia los grupos desaventajados del país, y así poder comenzar a hablar propiamente tal de derecho antidiscriminación como rama especializada de nuestro ordenamiento.

\section{Estándares internacionales y derecho antidiscriminación en la Unión Europea}

\subsection{Previo al positivismo, derechos humanos}

Estudiado ya el trascendental aporte que significó el proyecto de CE para la legislación antidiscriminación en Chile, al menos en lo que se refiere a su impulso, conviene destacar que es el derecho internacional de los derechos humanos el que consagra un nivel normativo básico de no discriminación. En virtud de ello, la Carta de Naciones Unidas en su Preámbulo indica: "Nosotros los pueblos de las Naciones Unidas resueltos... a reafirmar la fe en los derechos fundamentales del hombre, en la dignidad y el valor de la persona humana, en la igualdad de derechos de hombres y mujeres". También su artículo 1.3 consagra la cooperación internacional en el desarrollo y estímulo del respeto a los derechos humanos y libertades fundamentales de todos, "sin hacer distinción por motivos de raza, sexo, idioma o religión".

militar en Chile, cuestión que refleja la falta de teorización, protección y cultura de derechos humanos en el ordenamiento jurídico chileno.

Número de página no utilizable para citar 
Se destacó igualmente al inicio que los conocidos convenios de derechos humanos ratificados por Chile establecen definiciones más o menos amplias respecto al principio o derecho de igualdad. Pero, de acuerdo a Gauché (2014), "[f]ue la Organización Internacional del Trabajo (OIT) quien dio vida a la primera definición positiva internacional de discriminación en el Convenio de la Organización Internacional del Trabajo (111) relativo a la discriminación en materia de ocupación y empleo" en $1958^{18}$. Luego, diversos tratados fueron incluyendo definiciones en general similares sobre el concepto de discriminación, y con mayor precisión aún, el Comité de Derechos Humanos de la ONU, en su labor de supervisión y vigilancia del cumplimiento de las obligaciones del PIDCP, adoptó en su Observación General 18 una definición general de discriminación en su párrafo $7^{19}$, la cual constituiría una base para el desarrollo de posteriores tratados internacionales y legislaciones internas.

Bajo el concepto de los dos instrumentos citados, se desprende que la discriminación consiste en una desigualdad de tratamiento, basada en ciertos criterios o motivos (que la doctrina denomina "categorías sospechosas") que tienen por objeto menoscabar el goce y ejercicio de los derechos fundamentales en cualquier esfera de la vida pública o privada (Gauché, 2014: 16).

\subsection{Fundamentos generales del Derecho Antidiscriminación en la Unión Europea}

Convenio Europeo de Derechos Humanos, artículo 14 (Probibición de discriminación): "El goce de los derechos y libertades reconocidos en el presente Convenio ha de ser asegurado sin distinción alguna, especialmente por razones de sexo, raza, color, lengua, religión, opiniones políticas u otras, origen nacional o social, pertenencia a una minoría nacional, fortuna, nacimiento o cualquier otra situación".

Tratado de la Unión Europea, artículo 2 (Valores de la Unión): "La Unión se fundamenta en los valores de respeto de la dignidad humana, libertad, democracia, igualdad, Estado de Derecho y respeto de los derechos humanos, incluidos los derechos de las personas pertenecientes a minorías. Estos valores son comunes a los Estados miembros en una sociedad caracterizada

18 Convenio 111 OIT, artículo 1: "A los efectos de este Convenio, el término discriminación comprende cualquier distinción, exclusión o preferencia basada en motivos de raza, color, sexo, religión, opinión política, ascendencia nacional u origen social que tenga por efecto anular o alterar la igualdad de oportunidades o de trato en el empleo y la ocupación".

19 El párrafo 7 de la Observación General 18 indica que el término “discriminación”, tal como se emplea en el Pacto, debe entenderse como "toda distinción, exclusión, restricción o preferencia que se basen en determinados motivos, como la raza, el color, el idioma, la religión, el origen nacional o social, el nacimiento o cualquiera otra condición social, y que tengan por objeto o por resultado anular o menoscabar el reconocimiento, goce o ejercicio, en condiciones de igualdad, de los derechos humanos y libertades fundamentales de todas las personas".

Número de página no utilizable para citar 
por el pluralismo, la no discriminación, la tolerancia, la justicia, la solidaridad y la igualdad entre mujeres y hombres".

Tratado de la Unión Europea, artículo 3.3 párr. 2: "La Unión combatirá la exclusión social y la discriminación y fomentará la justicia y la protección sociales, la igualdad entre mujeres y hombres, la solidaridad entre las generaciones y la protección de los derechos del niño".

Ni los valores y principios de la Unión Europea recién citados, ni la disposición del Convenio Europeo, fueron ajenos a la redacción del proyecto de LAD chileno, teniendo en cuenta que la operación de Lisboa consistió en reformular los preceptos del proyecto de CE, el cual fue fuente inspiradora de la LAD. Es más, se mantuvo casi intacto el cuerpo de la Constitución Europea, la cual fue desprendida, eso sí, de revestimiento constitucional (Alonso, 2010: 51). No obstante ello, la doctrina ha entendido que ciertos principios establecidos en Lisboa, "como el de no discriminación o el de libre prestación de servicios, en ciertos casos, [pueden] ser asimilables a ciertas disposiciones relativas a la protección de los derechos humanos" (Canedo y Gordillo, 2008: 30).

La UE opera bajo la fórmula de organización supranacional, que si bien "no puede calificarse como de derecho constitucional" (Storini, 2012), los Estados miembros tras la ratificación Lisboa, han dotado a esta organización internacional de una mayor fuerza con la que antes no contaba: le han dado una personería jurídica, cuestión que se aprecia expresamente en el artículo $47 \mathrm{TUE}^{20}$. Que la Unión cuente con personalidad jurídica no es baladí, toda vez que el citado artículo viene a "cualificar a la UE para que, de un modo general, pueda actuar en el marco internacional en cuanto tal, es decir, como sujeto de Derecho internacional, (...) como persona jurídica diferente de los Estados miembros que la conforman y asumir, asimismo, su propia responsabilidad internacional" (Ramos, 2015) para el logro de sus objetivos y funciones.

Esto implica que, más allá de las tradiciones constitucionales comunes ${ }^{21}$ de los miembros de la Unión en materia de derechos humanos, ella desarrolla estándares propios, en consideración a que se ha insertado derechamente como sujeto de derecho internacional, con aptitudes para adquirir derechos y obligaciones y que toma decisiones propias. Por consiguiente, la promoción de la igualdad y el respeto por los derechos humanos ha sido un elemento central

20 Tratado de la Unión Europea, artículo 47: "La Unión tiene personalidad jurídica".

21 Las "tradiciones constitucionales comunes" de los Estados nacionales europeos miembros de la Unión son fuente de los principios generales del derecho europeo y también son instrumentos de interpretación de los derechos fundamentales, contribuyendo a la labor creativa del Tribunal de Justicia de la UE. En materia de derechos fundamentales, las tradiciones constitucionales comunes no están en discusión en cuanto a su labor, a diferencia de, por ejemplo, la identificación de estas tradiciones en la organización institucional de la organización (Ruiz Tarrías, 2009: 104). 
de las metas de la Unión, así como de su legislación e instituciones ${ }^{22}$, cuestión que mantiene hasta hoy.

En este sentido, Peter Reading ${ }^{23}$ ha reforzado la idea que la protección en contra de la discriminación es una cuestión que entra en el marco de los derechos humanos, desarrollo normativo fortalecido substancialmente por el Tratado de Lisboa. Este último instrumento, por lo demás, incorporó expresamente a la Unión como parte de la Carta Europea de Derechos humanos. Esta anexión expresa es relevante, puesto que si bien todos los Estados miembros de la UE ya eran parte del Convenio Europeo $(\mathrm{CEDH})$, ello no implicaba necesariamente que las mismas instituciones de la organización (como la Comisión Europea o el Parlamento Europeo) tuviesen que cumplir con las disposiciones de la Convención Europea de Derechos Humanos. Pero además de hacerla parte de la Carta, ésta última es muy similar en muchos aspectos al Convenio Europeo, de hecho, es un piso mínimo en cuanto al significado y alcance de los derechos consagrados en él (Academy of European Law, 2014). En efecto, se dice que el CEDH funciona como norma mínima, es decir, que los artículos de la Carta se interpretan de igual forma que los contenidos en el $\mathrm{CEDH}$, sin perjuicio que la Carta pueda ofrecer una mayor protección (Lock, 2009).

Amén de los valores esgrimidos en la $\mathrm{CE}$ y posteriormente en Lisboa, se encuentran antecedentes de esta férrea lucha contra la discriminación de la Unión Europea en anteriores decisiones del Consejo Europeo sobre discriminación, las cuales -del mismo modo en que la CEDH constituye una norma mínima de protección en relación a la Carta Europea- funcionan como criterios orientadores básicos para los países miembros. Se aprobó el 27 de noviembre de 2000 la Decisión del Consejo, por la que se establece un programa de acción comunitario para luchar contra la discriminación (2001-2006) o también denominada Framework Directive. Esta decisión provee protección a un grupo mucho más amplio que anteriores directivas ${ }^{24}$, en vista de que incluye consideraciones a creencias religiosas, orientación sexual, discapacidades y edad, además de restringir aún más los "casos" en donde la discriminación se considera prohibida.

Junto a los dos artículos 2 y 3.3 TUE citados, el TFUE en su artículo 19 prescribe una especie de acción antidiscriminación, en relación con la organización del funcionamiento de la UE y las

22 Por ejemplo, ya el Tratado de Roma (1957) exigía un pago igualitario para hombres y mujeres, además de prohibir la discriminación basada en el género de las personas en cuanto al acceso al empleo, entrenamiento y promoción vocacional y condiciones de trabajo.

23 Personero destacado en el ámbito de derechos humanos y protección de la igualdad en Europa, y desde el 2012 hasta la fecha, en Asia. Referencias a él se pueden encontrar en: https://www.eracomm.eu/antidiscri/e learning/kiosk/dokuments/cv reading.pdf

24 Anteriores directrices como la Race Directive (2000/43/EC), aprobada el mismo año que la Framework. Directive (2000/78/EC, lucha contra la discriminación), provee protección únicamente a las categorías de origen racial o étnico.

Número de página no utilizable para citar 
delegaciones de competencia ${ }^{25}$. Sumado a esto, el artículo 10 TFUE dispone que "[e]n la definición y ejecución de sus políticas y acciones, la Unión tratará de luchar contra toda discriminación por razón de sexo, raza u origen étnico, religión o convicciones, discapacidad, edad u orientación sexual", norma equiparable incluso al inciso 2 del artículo $1^{\circ}$ de la actual $\mathrm{LAD}^{26}$.

\subsection{Derecho Antidiscriminación en la Unión Europea: dogmática y tipos de discriminación}

Una definición general de discriminación apunta a que se trata de una violación del principio de igualdad ante o en la ley ${ }^{27}$ que radica en un tratamiento desigual entre ciudadanos, basado en ciertas características intrínsecas de la persona, lo cual suscita una desventaja o exclusión en desmedro de ciertos grupos (desaventajados) de la sociedad (Holtmaat, 2004; Miné, 2012) ${ }^{28}$.

25 Tratado de Funcionamiento de la Unión Europea, artículo 19.1. "Sin perjuicio de las demás disposiciones de los Tratados y dentro de los límites de las competencias atribuidas a la Unión por los mismos, el Consejo, por unanimidad con arreglo a un procedimiento legislativo especial, y previa aprobación del Parlamento Europeo, podrá adoptar acciones adecuadas para luchar contra la discriminación por motivos de sexo, de origen racial o étnico, religión o convicciones, discapacidad, edad u orientación sexual".

26 Ley 20.609 (LAD), artículo 1, inciso $2^{\circ}$ : "Corresponderá a cada uno de los órganos de la Administración del Estado, dentro del ámbito de su competencia, elaborar e implementar las políticas destinadas a garantizar a toda persona, sin discriminación arbitraria, el goce y ejercicio de sus derechos y libertades reconocidos por la Constitución Política de la República, las leyes y los tratados internacionales ratificados por Chile y que se encuentren vigentes".

27 La dogmática constitucional suele diferenciar dos conceptos generalmente tratados sinónimamente en las Constituciones nacionales: igualdad ante la ley, e igualdad en la ley. Respecto al primero, Holtmaat (2004: 6) indica que consiste en "un trato igualitario entre quienes se encuentran bajo una misma clasificación legal o una determinada aplicación de la ley", mientras que el segundo ordena al Estado crear "categorías (normas) legales que comprendan una igualdad de facto" [traducción propia].

En un sentido similar, y para clarificar más esta distinción, el Tribunal Constitucional Español en su sentencia 144/1998 explica la diferencia de ambos conceptos: "El principio de igualdad que garantiza la Constitución opera en dos planos distintos. De una parte, frente al legislador o frente al poder reglamentario, impidiendo que uno u otro puedan configurar los supuestos de hecho de la norma de modo tal que se dé trato distinto a personas que, desde todos los puntos de vista legítimamente adoptables se encuentren en la misma situación, o dicho de otro modo, impidiendo que se otorgue relevancia jurídica a circunstancias que, o bien no pueden ser tomadas nunca en consideración por prohibirlo así expresamente la propia Constitución, o bien no guardan relación alguna con el sentido de la regulación que, al incluirlas, incurre en arbitrariedad y es por eso discriminatoria". Esto corresponde a la igualdad en la ley. "En otro plano, en el de la aplicación, la igualdad ante la ley obliga a que ésta sea aplicada de modo igual a todos aquellos que se encuentran en la misma situación, sin que el aplicador pueda establecer diferencia alguna en razón de las personas, o de circunstancias que no sean precisamente las presentes en la norma".

28 "In common usage, to discriminate means to distinguish. However, in a legal sense, discrimination refers to disadvantageous treatment of an individual for a prohibited reason" (Miné, 2012). 
En cuanto a la diferenciación de tipos de discriminación, la experiencia chilena difiere de la europea. La Academy of European $\operatorname{Law}^{29}$ ha sistematizado los tipos de discriminación prohibidos en virtud de las Race Directive, Framework Directive, Gender Directive y la doctrina especializada. Cabe recordar que estas directivas del Consejo constituyen pisos normativos mínimos para la actividad legislativa o administrativa de los países miembros de la Unión.

Se considera que existe discriminación directa cuando una persona recibe un tratamiento menos favorable que otra en una situación comparable por motivos de origen racial o étnico (Conlan, 2012), por orientación sexual, creencias religiosas, u otra categoría. Se trata de una comparación de situaciones similares. Hipotéticamente, el demandante (discriminado) comparará su situación con respecto a otra persona en similares circunstancias, con la obligación de especificar expresamente ese cotejo (Braganza, 2014). La discriminación directa puede darse de jure o de facto. Refuerza esta concepción la fundación Interights ${ }^{30}$.

La Discriminación indirecta implica un trato igualitario con consecuencias desventajosas. El origen de este tipo de discriminación puede ser tanto una disposición, norma o práctica aparentemente neutral, mas ese criterio coloca a un grupo específico en especial desventaja. La doctrina nacional ha dicho que existe este tipo de discriminación cuando ocurre una distinción entre dos personas que, aun cuando no constituya discriminación directa, afecta particularmente a un grupo vulnerable y no se puede mostrar que la distinción haya sido "apropiada" en el contexto específico (Coddou, Schönsteiner y Vial, 2013).

Acoso u bostigamiento corresponde a una conducta no deseada, motivada por algún criterio protegido por las directives que tiene por objeto violar la dignidad de una persona, o generar mediante esa conducta un ambiente hostil, humillante, intimidante o degradante (MercatBruns, 2010). Adelantando un poco hacia el punto (c) de este trabajo, estimamos que la LAD no comprende este tipo de discriminación ni el siguiente.

Un cuarto tipo es la victimización. Los Estados miembros (de la Unión), en razón de las decisiones del Consejo deben introducir en sus sistemas legales medidas necesarias para proteger a los individuos de cualquier circunstancia o consecuencia adversa subsecuente a la denuncia entablada por discriminación. En el ámbito nacional, es lo que conocemos como

29 Consúltese su sitio oficial en: www.era.int

30 "The treatment given must be different to that which would have been afforded a person from a different relevant group in the same or comparable circumstances. Direct discrimination may occur when standard legal, political or economic rights or benefits are withheld from an individual or class of individuals on the basis of their membership of a certain group. This type of discrimination may be committed by public authorities, such as through national legislation, agency decisions, public appointments or budgetary allocations, or by private employers or organisations, such as through differential pay, delayed promotion or the refusal of entry to public amenities" (Interights, 2011). 
revictimización ${ }^{31}$. Este último tipo no es menos importante, pues, de no adoptar el Estado medidas conducentes a reducir la revictimización, las víctimas muchas veces preferirán callar y no denunciar discriminaciones, o cualquier acto que menoscabe su dignidad, con el fin de no verse expuestas nuevamente a una situación vulneratoria.

\subsection{Sobre la prueba de discriminación en el derecho europeo: cargas procesales y razonamiento judicial}

En la mayoría de los países europeos la discriminación es un ilícito civil (Cohen, 2012). Quien sufre un trato discriminatorio, naturalmente, se puede ver en una imposibilidad material de probar su pretensión jurídica (Barros, 2010) ${ }^{32}$, y esto significa concretamente, que la víctima generalmente se verá impedida de superar el estándar de prueba que el legislador establezca, el cual generalmente corresponderá al de prueba preponderante, toda vez que la aplicación del estándar que se ocupa en materia penal, es decir, más allá de toda duda razonable, en palabras del Tribunal Europeo, no permite alcanzar el objetivo de "garantizar derechos no teóricos e ilusorios, sino prácticos y efectivos"33. La duda razonable, por ende, no resulta adecuada en litigios antidiscriminación que generalmente versan sobre vulneración a algún derecho fundamental, y si no fundamental, al menos en lo que respecta a algún derecho que se siga de una calidad intrínseca de la víctima ${ }^{34}$, como la orientación sexual.

Aun así, el estándar de prueba preponderante -generalmente usado en materia civil- requiere que el demandante ofrezca prueba determinante que sea suficientemente convincente para el juzgador. Se dice que la prueba ofrecida por el litigante ganador habrá superado en un 50 más 1

31 A modo de ejemplo, cuando una mujer denuncia un acoso laboral o sexual, o una violación cometida en su contra, el Estado debe ser capaz de llevar a cabo un proceso en contra del autor del delito sin pasar a llevar nuevamente la integridad síquica o dignidad de la víctima mediante interrogatorios o procesos inidóneos que implicarían una revictimización de la persona.

32 "En otras ocasiones, sin embargo, la prueba de la culpa o de la causalidad puede ser en extremo dificultosa para la víctima, atendida la situación de desequilibrio estratégico en que se encuentra respecto del demandado (que controla la información) (...), de modo que bajo el principio general sobre carga de la prueba, lo más probable es que quede en la indefensión" (Resaltados añadidos) (Barros, 2010: 59).

El referido manual chileno es atingente al tema en comento, puesto que el litigio antidiscriminación, tanto en la práctica comparada como en Chile, se relega a la competencia civil, y el hecho discriminatorio no es sino un supuesto de responsabilidad extracontractual, al menos en los fundamentos de la LAD, aunque, con ciertos vicios que se verán infra.

33 La negación del estándar de prueba en materia penal para casos de discriminación se puede encontrar en las sentencias de los casos Artico vs. Italia (1980), Assenov vs. Bulgaria (1999) y Velikova vs. Bulgaria (2000), todos tramitados ante el TEDH.

34 Calidad intrínseca considerada socialmente como apartada de lo normal. El sujeto discriminador por sí mismo podrá constituir la norma y lo normal. "En cambio el 'otro' está marcado por su diferencia, que lo define y lo aparta de lo normal. Tal diferencia encuentra su correlato en su corporalidad, sea ésta femineidad, negritud, sexualidad desviada, enfermedad evidente, miseria, entre muchas otras formas de alteridad. Así, el 'otro' es física y moralmente débil, inferior, perverso, corrupto, miserable, abyecto" (Muñoz, 2011).

Número de página no utilizable para citar 
a la de la contraparte ${ }^{35}$. Por lo mismo, para superar esta dificultad, la ya comentada "Directriz sobre equidad racial" refleja un antecedente a la inversión de la carga de la prueba, en la cual la Unión Europea estableció un nuevo estándar de prueba en relación a demandas sobre discriminación:

"Una vez que la demandante acredita ciertos hechos que se presumen pueden constituir discriminación directa o indirecta, la carga de la prueba corresponde al demandado, quien deberá probar que no se ha violado el principio de igualdad de trato"36.

Corresponden estos casos a una inversión del onus probandi, pues en casos de discriminación se hace menester pensar cuidadosamente en quién debe soportar la carga de probar. Habrá situaciones en las cuales la víctima carecerá de evidencias (o le resultarán demasiado onerosas) que demuestren irrefutablemente que recibió un trato menos favorable, o que, frente a una norma aparentemente neutra, su situación es desventajosa (discriminación indirecta) (O'Dempsey, 2017; Beale, 2018). El requisito para alterar el onus probandi radicará en que el demandante construya una inferencia probatoria al juez del tipo "frente a la situación concreta, prima facie hubo un trato desigual". Una inferencia probatoria es la actividad que lleva a cabo el juez cuando conecta la información de que dispone (indicios, hechos probatorios, evidencia) con una hipótesis (los hechos a probar; estos hechos a probar no son otros que aquellos que puedan subsumirse en los supuestos de hecho genéricos que contempla la norma cuya aplicación se invoca (Carbonell, 2016). Esto vale decir, que el hecho a probar es la ocurrencia del hecho discriminatorio, a partir del hecho probatorio o base.

La prueba prima facie consiste en una apariencia de culpa que tiene como objetivo alterar el peso de la prueba ${ }^{37}$. El problema ahora es determinar cuándo se puede construir esa presunción de

35 Sobre el grado de convicción bajo el sistema de prueba prevaleciente en la jurisprudencia inglesa, véase Larroucau (2012): "si la evidencia es tal que el tribunal pueda decir 'pensamos que es más probable a que no', entonces la carga ha sido cumplida"; "el estándar de probabilidad prevaleciente o regla de P $>0,5$ ocupa un lugar de privilegio como umbral de prueba"; "un estándar de probabilidad prevaleciente (o regla P $>0,5)$ le imprime al juicio de hecho una racionalidad suficiente: si una de las posturas en competencia supera como grado de confirmación el 0,5 de probabilidad de ser correcta, entonces puede aceptarse como el soporte de la decisión".

36 Directiva del Consejo 2000/43/EC (2003, 21): "The rules on the burden of proof must be adapted when there is a prima facie case of discrimination and, for the principle of equal treatment to be applied effectively, the burden of proof must shift back to the respondent when evidence of such discrimination is brought".

37 "[E]n el derecho comparado se discute si la presunción referida no debe ser entendida más bien como una prueba en principio, consistente en la apariencia de culpa (...). En tales circunstancias, la presunción sólo alteraría el peso de la prueba mientras el demandado no muestre una explicación más razonable (...). Desbaratada de esa manera la presunción prima facie, la prueba de la diligencia correspondería al demandante, según las reglas generales; por el contrario, si el demandado no logra mostrar que hay razones para pensar que el daño ocurrió sin su culpa, resultaría responsable sobre la base de la prueba prima facie que permite la presunción. La regla establece esencialmente una alteración del riesgo de la prueba: si nada nuevo se logra probar, el efecto será que el demandante habrá acreditado la negligencia" (Resaltados añadidos) (Barros, 2010: 157). 
discriminación por parte del demandante, no obstante el TEDH generalmente acepta principios que son de lógica o de máximas de la experiencia, tales como si se trata de casos de discriminaciones históricas (e.g., mujeres, orientación sexual) o poca transparencia por parte del demandado. Lo determinante es que la víctima establezca fehacientemente el hecho base o probatorio, tanto en la prueba judicial (si hubiere), como en la presunción, el cual permitirá presumir la existencia de discriminación (Cohen, 2012).

En síntesis, en casos de discriminación en el derecho europeo, se presenta una carga de la prueba más "matizada y sutil", destinada a hacerse cargo de la dificultad histórica que ha significado establecer la discriminación en un tribunal de justicia, alejándose de la ortodoxia que rige la carga de la prueba (Rostant, 2017). El demandante deberá probar los "hechos primarios" (hechos probatorios o hecho base) que permitirán presumir la discriminación, como la situación fáctica de haber sido excluido o expulsado de un restaurant, sujeto al desafío procesal de presentar el hecho a probar, vale decir, la causalidad, el vínculo entre la categoría protegida y del trato que se queja contenido en el hecho probatorio.

La víctima en los sistemas europeos se ve envuelta en una protección jurídica que la exime de pruebas onerosas o imposibles, y esta institución es la presunción judicial ${ }^{38}$, que no hace otra cosa que conectar un hecho base o conocido (que la víctima ofrecerá) con un hecho desconocido o presunto (la situación de haber habido/haber discriminación) mediante un enlace o regla de presunción, "es decir, un enunciado general cuya aceptación autoriza el paso de uno a otro hecho" (Aguiló, 2006: 11).

Resulta relevante hacer estas clasificaciones, puesto que en general, en nuestro medio, se habla simplemente de "prueba", pero resulta fundamental que la víctima establezca claramente el hecho probatorio (o hecho base), pues de este último el juez extraerá la regla de presunción, garantía que servirá de enlace entre el primer hecho nombrado y el hecho a probar (hecho presunto, pretensión), el cual consistirá en aseverar que hay o hubo un trato discriminatorio.

Con todo, el demandado siempre tendrá la posibilidad de descargar o derrotar la presunción, y se prefiere que así sea, por encontrarse en una situación de superioridad material y fáctica para poder probar los hechos. "Una característica del razonamiento presuntivo es su derrotabilidad: aceptar una regla de presunción quiere decir que estamos dispuestos a modificar la conclusión si nueva información nos es proporcionada" (Aguiló, 2006: 12). Así pues, deberá el demandado

38 "En las [presunciones] judiciales, el juez debe construir un razonamiento basado en la experiencia y articulado lógicamente, que le permita establecer la relación entre dos hechos, uno conocido y otro que es inferido de aquél. Aunque, por lo general, la construcción de las presunciones judiciales es calificada como una cuestión de hecho, existen fallos que han establecido la doctrina, que parece ser correcta, en el sentido de que el juez sólo puede inferir hechos de otros hechos a condición de que muestre razonadamente que se cumplen los requisitos legales de gravedad (esto es, de proximidad a la certeza), precisión (esto es, de inequivocidad) y concordancia (esto es, de coherencia)" (Barros, 2010: 156). 
probar que no hubo un trato discriminatorio hacia la víctima, o de haberlo habido, deducirá ante el juez sus justificaciones, las cuales necesariamente, deben tener las características de razonabilidad y objetividad (fin legítimo) ${ }^{39}$, proporcionalidad entre los medios empleados ${ }^{40}$, o medidas de acción positivas (discriminación positiva).

Hay justificación objetiva y razonable cuando se persigue un fin legítimo, "que debe apreciarse en relación con la finalidad y los efectos de la medida examinada en atención a los principios que generalmente prevalecen en las sociedades democráticas" (Sarmiento, Mieres y Presno, 2007: 123).

En cuanto a la proporcionalidad, su determinación es compleja, toda vez que el Tribunal apreciará con detención las características socioculturales y normativas del país contratante, en el caso que el Estado sea el demandado. En atención a aquello, el juez mirará con cautela "los datos de hecho y de derecho que caractericen la vida en sociedad en el Estado que (...) responde de la medida impugnada" (Sarmiento, Mieres y Presno, 2007: 123)

El demandado por acción de no discriminación tendrá tres formas de oponerse a la presunción establecida en su contra (Aguiló 2006, 12-13):

i. Podrá controvertir la regla de presunción que utilice el juez, indicando que no tiene fundamento empírico, es decir, impugna su papel de garantía. Dirá que el razonamiento judicial que derivaría en imputación de responsabilidad por discriminación no comparte un tópico común entre los juristas o entre la ciencia o arte que requiera el litigio, es decir, la regla de presunción contradiría las máximas de la experiencia, las reglas de la lógica, o los conocimientos científicamente afianzados. Por ejemplo, las justificaciones de fin legítimo y medios proporcionales deben ser compartidas según alguno de los tres últimos criterios mencionados.

ii. $\quad$ Aceptar la regla de presunción (es decir, aceptar que expresa una regularidad con una alta probabilidad de verdad), pero negar la ocurrencia del hecho base; esto es, bloquear la presunción" (Aguiló, 2006: 13). Como se dijo supra, es riesgoso para el demandante no establecer fehacientemente el hecho probatorio, pues el demandado, de lograr controvertirlo, derrotará la presunción establecida en favor de la víctima.

39 "La igualdad de trato queda violada cuando la distinción carece de justificación objetiva y razonable. La existencia de una justificación semejante debe apreciarse en relación con la finalidad y los efectos en la medida examinada" (resaltados añadidos) (TEDH, Asunto relativo a ciertos aspectos del régimen lingüístico de la enseñanza en Bélgica, de 23 de julio de 1968).

40 "Una diferencia de trato en el ejercicio de un derecho consagrado por el Convenio debe perseguir una finalidad legítima; el artículo 14 se ve también violado cuando resulta claramente que no existe una razonable relación de proporcionalidad entre los medios empleados y la finalidad perseguida" (TEDH, Asunto relativo a ciertos aspectos del régimen lingüístico de la enseñanza en Bélgica, de 23 de julio de 1968). 
iii. "Aceptar tanto la regla de presunción como la ocurrencia del hecho base, pero exceptuar la regla de presunción mostrando, bien que la conclusión es falsa, bien que hay indicios para creer que el caso es una excepción a la regla" (Aguiló, 2006: 13). Una medida de acción positiva del demandado (discriminación positiva) constituiría una excepción a la regla de presunción de discriminación.

\section{La Ley 20.609, sobre antidiscriminación ("Ley Zamudio")}

Desarrollados los estándares internacionales y europeos sobre discriminación, sus clasificaciones doctrinarias, y sus efectos procesales, conviene ahora entrar de lleno en la LAD. Esta ley tiene como propósito único establecer un mecanismo judicial frente a actos de discriminación. Luego, ofrece una definición aparentemente compleja y completa de discriminación arbitraria en su artículo $2^{41}$, sin embargo, como se ha adelantado, la primera falencia sustantiva de la ley se produce al no hablar derechamente de discriminación: si se prohíbe la discriminación arbitraria (diferenciándose así nuestra legislación vergonzosamente de la práctica europea), ¿entonces, contrario sensu, se permitiría la discriminación no arbitraria? Pareciera que sí, por dos razones: en primer lugar, la ley mediante un contrapeso de derechos justifica de plano actos discriminatorios o tratamientos desiguales; y, por otro lado, lamentablemente nuestra jurisprudencia no ha sido capaz de hacer cumplir el espíritu de la ley, o en su defecto, hacer de esta acción judicial un mecanismo efectivo y no de papel.

Para abordar y sostener una crítica fundada a la legislación en comento, se vuelve imperioso contar con una definición íntegra que logre advertir elementos conceptuales claros y decisorios, respecto a qué es discriminación, y a partir de ella concretar los objetivos que debe llevar adelante el ordenamiento jurídico, pues ¿se quiere simplemente complejizar el sistema mediante acciones o mecanismos procesales inocuos, o erradicar y sancionar la discriminación en todas sus formas?

41 Ley 20.609, artículo $2^{\circ}$, inciso $1^{\circ}$. Definición de discriminación arbitraria. "Para los efectos de esta ley, se entiende por discriminación arbitraria toda distinción, exclusión o restricción que carezca de justificación razonable, efectuada por agentes del Estado o particulares, y que cause privación, perturbación o amenaza en el ejercicio legítimo de los derechos fundamentales establecidos en la Constitución Política de la República o en los tratados internacionales sobre derechos humanos ratificados por Chile y que se encuentren vigentes, en particular cuando se funden en motivos tales como la raza o etnia, la nacionalidad, la situación socioeconómica, el idioma, la ideología u opinión política, la religión o creencia, la sindicación o participación en organizaciones gremiales o la falta de ellas, el sexo, la orientación sexual, la identidad de género, el estado civil, la edad, la filiación, la apariencia personal y la enfermedad o discapacidad".

Número de página no utilizable para citar 
"[La discriminación es un] fenómeno social en virtud del cual la identidad adscriptiva de un sujeto, es decir, la identidad que se le adscribe socialmente (paradigmáticamente, el sexo/género, la raza/etnia/cultura, pero también la situación físico-mental y la ocupación/estatus de clase) conduce a que aquel sujeto reciba un tratamiento desventajoso en relación a otros sujetos. Esto se debe a que socialmente se construyen asimetrías entre identidades adscriptivas, asimetrías en virtud de las cuales un polo del binomio es valorado y su contraste es minusvalorado, ya sea porque una identidad adscriptiva en si es socialmente minusvalorada, o bien porque la identidad adscriptiva en cuestión es considerada anormal, esto es, desviada o deficitaria en relación con lo socialmente percibido como normal. (...) Discriminación [es], entonces, [e]l tratamiento desventajoso dado a un sujeto en consideración a su identidad adscriptiva; de manera más breve aún, la discriminación es desventaja adscriptiva" (Muñoz, 2015b: 173-74).

Evidentemente nuestra ley jamás intentó dar una definición tal, al contrario, la ley en sí no prohíbe la discriminación "a secas", sino que prohíbe y sanciona -muy relativamente- la discriminación arbitraria. La malograda definición legal de discriminación y la indefensión en la que deja a la víctima devela la simplicidad con la que se tramitó y se terminó promulgando la ley, sumada la poca teorización y adecuación a nuestro sistema sobre los tipos de discriminación que la doctrina y jurisprudencia comparada -y en menor medida la nacionalhan develado. Sobre esto, se ha dicho que la protección del sujeto discriminado es un proyecto aún en espera, en consideración a la poca efectividad de la ley en nuestro ordenamiento, además de sus disposiciones contradictorias para lograr el principio de igualdad y de no discriminación (Muñoz, 2015b: 190). En efecto, el radical cambio que hubo en la tramitación del proyecto permite avizorar la poca voluntad política para erradicar de la sociedad los actos discriminatorios efectuados contra cualquier persona, y mantener así la no discriminación como una preocupación de segunda categoría ${ }^{42}$. A continuación, los propósitos del proyecto original y de la ley promulgada:

Proyecto de ley original, Artículo $1^{\circ}$. "Las disposiciones de esta ley tienen por objeto prevenir y eliminar todas las formas de discriminación que se ejerzan contra cualquier persona".

Ley 20.609, Artículo 10, inciso 1".- Propósito de la ley. "Esta ley tiene por objetivo fundamental instaurar un mecanismo judicial que permita restablecer eficazmente el imperio del derecho toda vez que se cometa un acto de discriminación arbitraria".

42 Rolando Jiménez, vocero del Movimiento de Integración y Liberación Homosexual (MOVILH), en una entrevista concedida a la Dirección de Estudios de la Corte Suprema, indicó que "La Ley 20.609 considera además que es posible discriminar en virtud del ejercicio de otros derechos constitucionales. Así, el derecho a no ser discriminado es de segunda categoría” (Dirección de Estudios Corte Suprema, 2018: 88) 
Ante todo, si originalmente se deseaba "prevenir y eliminar todas las formas de discriminación", el propósito actual de la ley no es sino establecer una mera acción judicial frente a actos de discriminación arbitraria, cuestión que resulta además poco accesible, en vista de que posteriormente al describir la discriminación arbitraria e indicar casi taxativamente sus causales $^{43}$, indica de plano que "se considerarán razonables las distinciones (...) que no obstante fundarse en algunos de los criterios mencionados (...), se encuentren justificadas en el ejercicio legítimo de otro derecho fundamental" (LAD artículo 2, inciso $2^{\circ}$ ). Esto es un vuelco categórico a las exclusiones del principio de no discriminación que se sigue en el derecho de la Unión Europea: mientras los tribunales europeos exigen como justificación al tratamiento discriminatorio la persecución de un fin legítimo, exigido en el Asunto relativo a ciertos aspectos del régimen lingüistico de la enseñanza en Bélgica, de 23 de julio de 1968 (analizado en perspectiva a los medios empleados y la finalidad perseguida ${ }^{44}$ ), nuestra ley lo justifica sin exigencias, más que actuar en ejercicio de otro derecho.

La LAD reconoce desde un principio, al dar a conocer su propósito, que para ella es imperioso restablecer el imperio del derecho, pero no frente a un acto de discriminación en sentido amplio, sino que únicamente cuando ese hecho sea calificado como arbitrario. En principio se podría tolerar que la ley usara el adjetivo "arbitrario" frente a un hecho que importa un tratamiento desventajoso, puesto que naturalmente se esperaría que en el proceso judicial se conociera el resto de los hechos, y de ellos, extraer eventuales justificaciones a favor del demandado. Sin embargo, la ley pareciera justificar de plano estos hechos en su artículo $2^{\circ}$, y en añadidura, lamentablemente nuestros tribunales han interpretado sus disposiciones en desmedro de las víctimas ${ }^{45}$.

Alejándose así del derecho antidiscriminación europeo, es la ley en su artículo $2^{\circ}$ la que determina justificado y razonable un trato desigual, cuando se ha fundado en ejercicio de cualquier derecho fundamental, y “en especial, los referidos a” la vida privada y honra; la

43 Respecto a una enumeración de causales muy exhaustiva e inclusiva (como la presente en el art. 2 LAD), se ha dicho que resulta jurídicamente innecesario, dado que, en la realidad, la lista "no es de numerus clausus y la inclusión de menciones adicionales podría propiciar una interpretación no deseable que amparara discriminaciones basadas en motivos no mencionados" (Sarmiento, Mieres y Presno, 2007: 119).

44 "Cuando la distinción carece de justificación objetiva y razonable la igualdad de trato queda violada. La existencia de una justificación razonable debe apreciarse en relación con la finalidad y los efectos de la medida examinada en atención a los principios que generalmente prevalecen en las sociedades democráticas (...) [:] proporcionalidad entre los medios empleados y la finalidad perseguida" (Sarmiento, Mieres y Presno, 2007: 669). Resaltado añadido de manera indicativa a que la acción presuntamente discriminatoria es algo que el tribunal examina, en la medida en que las partes ofrecen la prueba. No resulta deseable, por tanto, que la ley, de plano, determine justificado un trato desigual.

45 "Más escuálida aún es la genuina contribución de dichas sentencias a la protección legal de las categorías de sujetos adscriptivamente desaventajados; o sea, a la protección legal del sujeto discriminado. Sólo un 27.3\% de las sentencias son favorables a la pretensión de la demandada. De entre las nueve sentencias que acogen la acción, una de ellas, Easton con Federación de Rodeo, no tiene absolutamente nada que ver con la discriminación en cuanto fenómeno social. En cambio, entre las sentencias que rechazan la demanda, se cuentan gravísimos y evidentes casos de discriminación" (Muñoz, 2015b: 190).

Número de página no utilizable para citar 
libertad de conciencia, creencias y cultos; libertad de enseñanza; libertad de opinión; libre asociación; libertad de trabajo; y libertad económica (estos son los derechos fundamentales del artículo 19 números 4, 6, 11, 12, 15, 16 y 21 de la Constitución Política de la República), o "en otra causa constitucionalmente legítima". Es problemático que sea la ley, y no el trabajo judicial fruto de un litigio con cargas procesales definidas, como ocurre en la práctica comparada, la que decida previamente que un trato desigual tenga el carácter de "razonable" simplemente cuando se cumpla el requisito de ejercicio legítimo de un derecho fundamental. Frente a los estándares de la Unión, la ley ya presenta debilidades en la protección de los principios de no discriminación y de igualdad de trato, al declarar de jure una justificación razonable del acto discriminatorio, justificación insuficiente por lo demás para la doctrina y jurisprudencia comparada.

Interpretada extensivamente por nuestros tribunales la frase "o en otra causa constitucionalmente legítima", cabría en ese precepto el cumplimiento irrestricto de leyes vigentes, discriminatorias o no. Así, en la sentencia Leal con $L A N^{46}$ y Valdebenito con Soto ${ }^{47}$, los sentenciadores han indicado que el trato discriminatorio debe "encontrar sustento en el ordenamiento jurídico", y que "no se admitirá a tramitación la acción cuando se impugnen los contenidos de leyes vigentes" (resaltados añadidos).

Además de un texto legal que no se condice con los estándares que tanto su mensaje presidencial como su tramitación propició sobre la materia, "las sentencias en conjunto no están logrando impactar significativamente en la sociedad modificando mentalidades y patrones conductuales" (Muñoz, 2015b: 191), es más, hasta el año 2015 sólo 12 de 45 demandas deducidas por Ley Zamudio fueron acogidas por los tribunales, y hasta diciembre de 2016 la cifra se mantenía oscura, pues un 56\% de las demandas fueron desestimadas (Dirección de Estudios Corte Suprema, 2018: 100). A lo que me he referido radica en problemas previos tan profundos como la exigua cultura jurídica en no discriminación, o el mismo texto legal. La LAD a priori justifica exclusiones o discriminaciones en razón del ordenamiento jurídico vigente, muy contrariamente al ideal del proyecto original, y asimismo, distinto al derecho europeo, el cual jamás justifica actos discriminatorios de jure (como lo hace la Ley Zamudio), ni los justifica por estar actuando bajo la legislación vigente (como lo hace la judicatura).

Considerando el tratamiento que dan nuestros tribunales al ordenamiento positivo vigente -nos referimos a la imposibilidad de impugnar contenido legal, por discriminatorio que sea-, cabe comparar nuestra jurisprudencia con la del Tribunal Europeo, donde este último ha encontrado responsabilidad de los Estados no sólo por carecer de mecanismos efectivos de

46 Rol C-6545-2013 del $1^{\circ}$ Juzgado Civil de Temuco.

47 Rol C-3081-2013 del 1º Juzgado Civil de Valparaíso.

Número de página no utilizable para citar 
lucha contra la discriminación efectuada tanto por agentes de su orgánica estatal o por particulares $^{48}$, sino que incluso, es perfectamente impugnable ante el TEDH y condenable una normativa vigente que se estime contraria al principio de no discriminación, como se puede apreciar en las sentencias sobre el Asunto relativo a ciertos aspectos del régimen lingüistico de la enseñanza en Bélgica y el Asunto Thlimmenos c. Grecia ${ }^{49}$.

Continuando con el estudio a la ley en cuestión, ella no sólo soslaya los tipos de discriminación ampliamente comentados por la doctrina europea en un concepto vago y errado (discriminación arbitraria), sino que además, adolece de otros vicios que hacen de su aplicación algo muy complejo para los demandantes. En cuanto a la carga de la prueba, la LAD no innova respecto de las reglas del Código Civil, el cual en su artículo 1698 indica que "incumbe probar las obligaciones o su extinción al que alega aquéllas o ésta". En sentido amplio, la Ley Antidiscriminación mantiene la carga de probar a quien alega un hecho discriminatorio. En principio, se podría sostener que esto no es problemático, teniendo en consideración que el litigio antidiscriminación es un asunto civil, no obstante, como se vio en el apartado (b), la dogmática ha reiterado que en estos casos de difícil o imposible prueba, el onus probandi debe invertirse en favor del demandante.

El hecho que la ley no establezca variaciones a la carga de la prueba, quedándose en los infranqueables principios civiles sobre la materia, implica que esta (mera) acción judicial de no discriminación constituya una tutela ilusoria de protección a los principios de igualdad de trato y de no discriminación.

Se refleja esta tutela ilusoria también, en que la LAD, contraintuitivamente a sus principios civiles no contempla indemnizaciones a la víctima. En efecto, en la sentencia Ojeda con SERCOTEC ${ }^{50}$, el Tribunal asevera que "el objetivo de la Ley Zamudio, (...) [es] restablecer las cosas al estado

48 Véase Asunto Xe Y con Países Bajos: "The Court found the protection afforded by civil law to be insufficient where fundamental values and essential aspects of private life are at stake. Effective deterrence from committing further crimes is indispensable and can only be achieved by criminal law. Therefore, the Netherlands criminal code provision that required a complaint to be made by the actual victim before criminal proceedings can be instituted presented a clear procedural gap in the law in respect of minors and the people with a mental disability and did not provide $\mathrm{Y}$ with practical and effective protection".

49 Ver Sarmiento, Mieres y Presno (2007: 677-78; 684):

- Asunto relativo a ciertos aspectos del régimen lingüístico de la enseñanza en Bélgica: "Una medida así [la impugnada] no se justifica a la vista de las exigencias del Convenio, en la medida en que comporta, en detrimento de ciertos individuos, los elementos de un trato discriminatorio fundado más sobre la lengua que sobre la residencia"; "En otros términos, la medida impugnada se revela a este respecto incompatible con la primera frase del artículo 2 del Protocolo, combinado con el artículo 14 del Convenio";

- Asunto Thlimmenos c. Grecia: "[La ley interna] no permite al Estado demandado declinar cualquier responsabilidad de acuerdo con el Convenio (...) El estado, al aprobar la legislación correspondiente sin introducir las excepciones apropiadas (...) ha vulnerado el derecho del demandante que prohíbe la discriminación en el goce de su derecho establecido en el artículo 9 de la Convención".

50 Rol C-479-2014 y C-1303-2014 (ambas rechazadas). 
normal, no otra cosa"51. Y como si esto fuera poco, en la misma línea del mantenimiento de tales principios tradicionales, el Tribunal puede imponer al demandante una multa ascendente a 20 unidades tributarias mensuales, "si se estableciere que la denuncia ha sido carente de todo fundamento" (Dirección de Estudios Corte Suprema, 2018: 112), siendo esto otro desincentivo más a denunciar, además de las difíciles trabas procesales probatorias.

Se percibe entre los efectos de la ley un mantenimiento del status quo, en el sentido que ella -ni los tribunales- no ha intentado erradicar la discriminación del entorno social, sino que mediante una acción judicial carente de fuerza, legitima la discriminación en virtud de, aparentemente, derechos más importantes que otros, cuando en verdad, "[1]os derechos existen sólo en relación con otros derechos, reivindicaciones de derechos que implican el conocimiento de otros y de sus derechos y de redes transnacionales de reconocimiento mutuo" (Douzinas, 2006).

Si se estimó necesario el establecimiento de una acción especial antidiscriminación, fue precisamente porque nuestra práctica jurisprudencial sugirió que el numeral $2^{\circ}$ del artículo 19 de la Constitución Política de la República no cooperaba con instancias de discriminación, al menos, en razón de la orientación sexual (Couso, 2012: 198), y lamentablemente, sin obviar el avance simbólico, esta ley "no posee los instrumentos ni categorías, ni provee los medios a los órganos del Estado para combatir eficazmente [la] discriminación" (Coddou, Schönsteiner y Vial, 2013: 308).

\section{Conclusiones}

Con lo expuesto se contrapone el estado del derecho antidiscriminación chileno con el existente en la Unión Europea. Como se vio, Chile está al debe con los grupos desaventajados del territorio, en el sentido que presenta un mecanismo judicial inidóneo para terminar con situaciones discriminatorias que les afecten. Recientemente un grupo de parlamentarios ha anunciado una eventual reforma a la Ley Antidiscriminación (Boletín $N^{\circ}$ 10.035-17 del Senado), por lo que la comunidad jurídica debe estar atenta a los cambios venideros. También,

51 “QQué 'otra cosa' no constituye el objetivo de la ley? Al parecer, de aquello de lo que no se trata la Ley Zamudio es de reorganizar el entorno para adecuarlo a las necesidades diferenciadas de personas diferentes" (Muñoz, 2015a, 153); además, respecto de la sentencia Peña con Escuela Especial de Lenguaje (rol C-1527-2013), el autor en la misma página indica que "[e]n esta sentencia, el tribunal declaró que «se desestima [sic] cualquier alegación que exceda el catálogo de derechos, libertades e igualdades establecidos en su artículo 19» (...). Nuestra jurisprudencia considera que, respecto de una persona con necesidades especiales, el no ser incluido no es discriminación”.

Número de página no utilizable para citar 
se espera que los jueces puedan dotar de efectividad a la ley en el tiempo próximo, pues, si el legislador no fue lo suficientemente perspicaz para tener una ley antidiscriminación eficaz y concordante con los estándares internacionales, son ellos quienes, sin prevaricar, pueden dar el sentido correcto a la ley, permitiendo, e.g., alterar la carga de la prueba en litigios antidiscriminación, toda vez que no hay ninguna disposición en la ley ni en el Código Civil que prohíba aquello. Pero para esto, como todo cambio sociopolítico, habrá que esperar.

Por lo demás, quedan pendientes todavía temas muy relevantes que el derecho antidiscriminación debe hacerse cargo: se debe llegar a una ley de matrimonio civil íntegra, que comprenda tanto a parejas de distinto o igual sexo, mediante una reforma al artículo 102 del Código Civil, y no simplemente legislar un mal llamado matrimonio homosexual o igualitario (Martín Sánchez, 2016: 220). También, aún quedan resabios en nuestro ordenamiento de la antigua ley de sodomía, respecto a la prohibición penal de la homosexualidad masculina juvenil en el artículo 365 del Código Penal, temas todos a ser tratados de manera seria por el legislador, para que los y las discriminadas no deban simplemente "morderse la lengua y salir adelante" (Tijoux, 2002) frente a la ineficacia del derecho.

\section{Referencias bibliográficas}

BEALE, Anna (2018). «Proving discrimination: the sift of the burden of proof and access to evidence». Editado por Academy of European Law. http://www.eracomm.eu/oldoku/Adiskri/03_Burden_of_proof/118DV18_Beale_Paper_EN.pdf (último acceso: 18 de diciembre de 2018).

Biblioteca del Congreso Nacional (2005). «Historia de la ley 20.609». Biblioteca del Congreso Nacional. https://www.bcn.cl/historiadelaley/nc/historia-de-la-ley/4516/ (último acceso: 18 de diciembre de 2018).

BRAGANZA, Nicola (2014). «European Union (EU) anti-discrimination law» En Academy of European Law, European Union (EU) anti-discrimination law. Trier: ERA: 19-28. http://www.era-comm.eu/anti-discri/e_learning/kiosk/dokuments/Anti-discriprint.pdf

CoHEN, Barbara (2012). «Proving discrimination: Evidence and the Burden of Proof». Editado por Academy of European Law. http://www.eracomm.eu/oldoku/Adiskri/03_Burden_of_proof/2012_Cohen_paper_EN.pdf (último acceso: 18 de diciembre de 2018). 
CONlan, Patricia (2012). «The EU anti-discrimination directives and definitions of key concepts». Editado por Academy of European Law. Definitions of key concepts: AntiDiscrimination Documentation, speaker's contributions. http://www.eracomm.eu/oldoku/Adiskri/02_Key_concepts/2012_Conlan_EN.pdf (último acceso: 18 de diciembre de 2018).

ERA, ACADEMY OF EUROPEAN LAW (2014). «European Union (EU) anti-discrimination law». Trier: ERA. http://www.era-comm.eu/anti-discri/e_learning/kiosk/dokuments/Antidiscri-print.pdf (último acceso: 18 de diciembre de 2018).

HoltmaAT, Rikki (2004). «The concept of discrimination» Conference The fight against discrimination in the daily practice. http://www.eracomm.eu/oldoku/Adiskri/02_Key_concepts/2004_Holtmaat_EN.pdf (último acceso: 18 de diciembre de 2018).

LOCK, Tobias (2009). «Relación de la Carta con respecto al CEDH y a las disposiciones nacionales de los derechos humanos». En http://www.eracomm.eu/charter_of_fundamental_rights/kiosk/pdf/413DT59_Barcelona/Lock_EU _CHR_ES.pdf (útlimo acceso: 18 de diciembre de 2018).

Mercat-Bruns, Marie (2010). «Introduction to EU legislation and definitions of key concepts: Direct discrimination, Indirect discrimination, Harassment». En htttp://www.era-

comm.eu/oldoku/Adiskri/02_Key_concepts/2010_04_MercatBruns_EN.pdf (último acceso: 18 de diciembre de 2018).

MinÉ, Michael (2012). «Concepts of direct and indirect discrimination». En Conference The Fight Against Discrimination, New Directives of 2000 Concerning Equality, http://www.era-comm.eu/oldoku/adiskri/02_key_concepts/2003_mine_en.pdf

(último acceso: 18 de diciembre de 2018).

NACIONES UNIDAS (1989). «Observación General 18». En www.ohchr.org/Documents/HRBodies/TB/HRI-GEN-1-REV-9-VOL-I_en.doc (último acceso: 18 de diciembre de 2018).

O'DEMPSEY, Declan (2017). «Proving discrimination: The Burden of proof». Editado por Academy of European Law. Diciembre de 2017. http://www.eracomm.eu/oldoku/Adiskri/02_Key_concepts/2006_ODempsey_EN.pdf (último acceso: 18 de diciembre de 2018). 
Rostant, Philip (2017). «The burden of proof and access to justice in discrimination cases». Editado por Academy of European Law. Noviembre de 2017. http://www.eracomm.eu/oldoku/Adiskri/03_Burden_of_proof/117DV36_Rostant_paper.pdf (último acceso: 18 de diciembre de 2018).

Unión EuropeA, Consejo Europeo (2005). «Proyecto de Constitución Europea» https://europa.eu/europeanunion/sites/europaeu/files/docs/body/treaty_establishing_a_constitution_for_europe _es.pdf (último acceso: 18 de diciembre 2018).

AGuiló, Josep (2006). «Presunciones, verdad y normas procesales». Isegoría, 35, Julio-Diciembre: 9-31.

Alonso, Ricardo (2010). Sistema jurídico de la Unión Europea. Segunda Edición. Madrid: Thomson Reuters-Civitas.

BArros, Enrique (2010). Tratado de Responsabilidad Extracontractual. Segunda Edición. Santiago: Editorial Jurídica de Chile.

BORDALÍ, Andrés (2001). «El recurso de protección chileno al banquillo». Revista del Instituto de Ciencias Jurídicas de Puebla, 5 (27): 56-71.

CANedo, José, y Luis Gordillo (2008). «Los Derechos Fundamentales en la Unión Europea a la Espera de Lisboa». Cuadernos Europeos de Deusto, 39: 27-59.

CARbOnell, Flavia (2016). «Presunciones y verdad» (manuscrito), Jornadas Chilotas de Derecho. Chiloé.

CoDDou, Alberto, Judith Schönsteiner, y Tomás Vial (2013). «La Ley Antidiscriminación: Avances e insuficiencias en la protección de la igualdad y la no discriminación en Chile». Informe anual sobre derechos humanos en Chile (Universidad Diego Portales): 185-208.

Couso, Javier (2012). «Acerca de la pertinencia de la nueva ley de no discriminación para combatir la estigmatización de los homosexuales en Chile». Revista de Derecho Público Iberoamericano, 1: 193-199.

DireCCiÓn DE ESTUdios CORTE SuPREMA (2018). «Análisis Estadístico de la Ley 20.609: Una mirada desde el acceso a la justicia a cinco años de su vigencia» Revista DECS: 74-121.

DouZINAS, Costas (2006). «El fin(al) de los derechos humanos». Anuario de derechos humanos de la Universidad Complutense de Madrid, 7: 309-340. 
GAUCHÉ, Ximena (2014). «Análisis crítico de la Ley 20.609, que establece medidas contra la discriminación, a la luz del derecho internacional de los derechos humanos y las convenciones de la OEA». Revista Chilena de Derecho y Ciencia Política, 5 (1): 11-58.

GuineA, Mercedes, y Francisco Aldecoa (2008). La Europa que viene: El Tratado de Lisboa. Madrid: Marcial Pons.

HunTER, Iván (2017). «Reglas de prueba legal y libre valoración de la prueba: ¿Cómo conviven en el Proyecto de Código Procesal Civil?» Ius et Praxis, (1): 247-272.

INTERIGHTS, Inernational Center for the Legal Protection of Human Rights (2011). NonDiscriminationin in International Law. A Handbook for Practitioners. Interights.

JURI, Juan Carlos (2013). Los derechos humanos en la Unión Europea, antes y después del Tratado de Lisboa (Tesis). Santiago: Facultad de Derecho, Universidad de Chile.

LARROUCAU, Jorge (2012). «Hacia un estándar de prueba civil». Revista Chilena de Derecho, 39 (3): 783-808.

MARTín SÁNCHEZ, María (2016). «Los derechos de las parejas del mismo sexo en Europa. Estudio Comparado». Revista Española de Derecho Constitucional, (107): 219-253.

MARtín Y PÉREZ DE NANClares, José (2003). «El proyecto de Constitución Europea: Reflexiones sobre los trabajos de la Convención». Revista de Derecho Comunitario Europeo, (15): 527-572.

MAturanA, Cristián, y Mario Mosquera (2012). Los recursos procesales. Segunda Edición. Santiago: Editorial Jurídica de Chile.

MuÑOZ, Fernando (2011). «No a separados pero iguales en Chile: un análisis del derecho antidiscriminación chileno a partir de su primera sentencia». Estudios Constitucionales, (2): 201-228.

MuÑOZ, Fernando (2015a). «Estándares conceptuales y cargas procesales en el litigio antidiscriminación. Análisis crítico de la jurisprudencia sobre Ley Zamudio entre 2012 y 2015». Revista de Derecho de Valdivia, 28 (2): 145-167.

MuÑOZ, Fernando (2015b). «La Ley Zamudio en acción: sentencias de primera instancia sobre acción antidiscriminación emitidas entre diciembre de 2012 y marzo de 2015». Anuario de Derecho Público: 172-191. 
Ortega, Martín (2001). «iViva la Constitución Europea!». Política Exterior, 15 (82): 87-98.

RAMOS, Belén Sánchez (2015). La Unión Europea como actor global: Algunas cuestiones analizadas desde el Tratado de Lisboa. España: Tirant Lo Blanch.

RUIZ TARríAS, Susana (2009). «Las 'tradiciones constitucionales comunes' en el ordenamiento europeo. Su valor jurídico en el Tratado de Lisboa». En Francisco Matia (director), Estudios sobre el Tratado de Lisboa: 95-111. Granada: Comares.

SARMIENTO, Daniel, Luis Mieres, y Luis Presno (2007). Las sentencias básicas del Tribunal Europeo de Derechos Humanos. Cizur Menor, Navarra: Thomson Civitas.

Serrano, Gerardo (2010). «La Génesis Del Tratado De Lisboa». Cuadernos de Pensamiento Político, (25): 135-162.

STORINI, Claudia (2012). «El Tratado de Lisboa. ¿Un paso adelante hacia la “parlamentarización” de la Unión Europea?» Derecho del Estado, (28): 115-141.

Tijoux, María Emilia (2002). «Morderse la lengua y salir adelante». Amérique Latine Histoire Et Mémoire. http://journals.openedition.org/alhim/639 (último acceso: 18 de diciembre de 2018). 